\title{
The role of digital clinical decision support tool in improving quality of intrapartum and postpartum care: experiences from two states of India
}

Gulnoza Usmanova ${ }^{1}$, Kamlesh Lalchandani ${ }^{1}$, Ashish Srivastava ${ }^{1}$, Chandra Shekhar Joshi ${ }^{1}$, Deepak Chandra Bhatt ${ }^{\text {* }}$, Anand Kumar Bairagi', Yashpal Jain ${ }^{1}$, Mohammed Afzal ${ }^{1}$, Rashmi Dhoundiyal', Jyoti Benawri ${ }^{1}$, Tarun Chaudhary², Archana Mishra ${ }^{3}$, Rajni Wadhwa ${ }^{4}$, Pompy Sridhar ${ }^{5}$, Nupur Bahl ${ }^{6}$, Pratibha Gaikwad ${ }^{7}$ and Bulbul Sood ${ }^{1}$

\begin{abstract}
Background: Computerized clinical decision support (CDSS) -digital information systems designed to improve clinical decision making by providers - is a promising tool for improving quality of care. This study aims to understand the uptake of ASMAN application (defined as completeness of electronic case sheets), the role of CDSS in improving adherence to key clinical practices and delivery outcomes.

Methods: We have conducted secondary analysis of program data (government data) collected from 81 public facilities across four districts each in two sates of Madhya Pradesh and Rajasthan. The data collected between August -October 2017 (baseline) and the data collected between December 2019 - March 2020 (latest) was analysed. The data sources included: digitized labour room registers, case sheets, referral and discharge summary forms, observation checklist and complication format. Descriptive, univariate and multivariate and interrupted time series regression analyses were conducted.
\end{abstract}

Results: The completeness of electronic case sheets was low at postpartum period (40.5\%), and in facilities with more than 300 deliveries a month (20.9\%). In multivariate logistic regression analysis, the introduction of technology yielded significant improvement in adherence to key clinical practices. We have observed reduction in fresh still births rates and asphyxia, but these results were not statistically significant in interrupted time series analysis. However, our analysis showed that identification of maternal complications has increased over the period of program implementation and at the same time referral outs decreased.

Conclusions: Our study indicates CDSS has a potential to improve quality of intrapartum care and delivery outcome. Future studies with rigorous study design is required to understand the impact of technology in improving quality of maternity care.

Keywords: Intrapartum care, Postpartum care, Maternal health, New-born health, CDSS, mHealth, Health information technology, Quality improvement

\footnotetext{
* Correspondence: deepakbhatt001@gmail.com

1Jhpiego-An Affiliate of Johns Hopkins University, New Delhi 110020, India

Full list of author information is available at the end of the article
}

C C The Author(s). 2021 Open Access This article is licensed under a Creative Commons Attribution 4.0 International License, which permits use, sharing, adaptation, distribution and reproduction in any medium or format, as long as you give appropriate credit to the original author(s) and the source, provide a link to the Creative Commons licence, and indicate if changes were made. The images or other third party material in this article are included in the article's Creative Commons licence, unless indicated otherwise in a credit line to the material. If material is not included in the article's Creative Commons licence and your intended use is not permitted by statutory regulation or exceeds the permitted use, you will need to obtain permission directly from the copyright holder. To view a copy of this licence, visit http://creativecommons.org/licenses/by/4.0/ The Creative Commons Public Domain Dedication waiver (http://creativecommons.org/publicdomain/zero/1.0/) applies to the data made available in this article, unless otherwise stated in a credit line to the data. 


\section{Introduction}

Globally, it has been proven that effective and quality of care at the facility level, particularly around childbirth and immediately after the birth, can significantly contribute to the reduction of maternal deaths, stillbirths and neonatal deaths $[1,2]$. Over the last decades, efforts in ensuring skilled birth attendance resulted in increased institutional deliveries, this in turn moved higher proportion of avoidable maternal and neonatal mortality to health facilities [2]. Therefore, improving quality of care around childbirth and immediately after birth is imperative to prevent adverse outcomes for pregnant women and new-borns [2].

In India, despite a tremendous increase in rate of institutional deliveries [3], maternal and neonatal deaths did not show equivalent reduction [4] in the last decade. It was found by few studies that the increase in the rate of institutional deliveries was not matched with overall improvement in quality of maternity care [4-6]. Quality of care is a multi-dimensional concept that incudes availability of evidence based guidelines, strengthened infrastructure, resources, enabling environment, attitude of health providers; all these in turn result in patients' and providers' satisfaction and improved health outcomes [2]. To address these issues the, Government of India (GoI), launched the quality improvement initiative under the name 'Dakshata' (means adroitness) [7], to build provider adherence to key evidence based clinical practices during intrapartum and immediate postpartum periods. Dakshata uses the World Health Organization's Safe Childbirth Checklist (SCC) as a framework for improving providers' competency. Although, Dakshata intervention has not been evaluated, other quality of intrapartum care improvement initiatives using SCC in Rajasthan [8], Uttar Pradesh [9] and Karnataka [10] demonstrated significant improvement in adherence to evidence based clinical practices. Moreover, a study from Rajasthan showed reduction in perinatal mortality, which fell by $11 \%$ [11]. However, these studies detected certain clinical practices that either did not improve significantly (initiation of partograph, counselling on danger signs), or declined over 12 months' period (use of SCC, administration of oxytocin soon after delivery). Thus, it is imperative to identify and test innovative solutions for improving quality of care in order to accelerate reduction in maternal and neonatal death in India. One such solution is computerized clinical decision support (CDSS) -digital information systems designed to improve clinical decision making by providers - a promising tool for improving quality of care by improving adherence to clinical guidelines [12, 13], practitioner's performance [12, 14], patient outcomes [15-17], and quality of clinical documentation [18], thus contributing to quality improvement and overall efficiency of health care delivery. While there is significant research on CDSSs generally, but evidence of use of CDSS for maternity care is limited. In rural health facilities in Burkina Faso, Ghana and Tanzania, CDSS was not found to significantly improve quality of antenatal and delivery care [19]. A study conducted in South Africa showed that CDSS lead to overall improvement in adherence to clinical guidelines, but it was not statistically significant [20]. In Nigeria, McNabb et al., reported that decision support via mobile phones led to significant improvement in health counselling, technical services, quality of health education and patient satisfaction [21].

\section{ASMAN intervention}

In this paper we describe the findings from implementation of "ASMAN" (The Alliance for Saving Mothers and Newborns) a provider-focused package of interventions that leverages technology to reduce maternal and early neonatal mortality through the adoption of key technologies that improve capacity-building and service delivery efforts focused on the provision of quality care during childbirth and the first 48-60 h after delivery.

The ASMAN project takes an integrated quality improvement approach:

1. Competency building - through provision of training for Medical Officers (MOs), Staff Nurses, Auxiliary Nurse Midwife (ANM) on clinical skills and quality of care as per the established labour room protocols and standards. For this purpose, the project adopted GoI approved Dakshata training package for building the capacity of service providers. Post training follow up and on-site mentoring were conducted by the program team to ensure translation of skills into practice.

2. Introduction of technology intervention to facilitate timely and correct clinical decision-making by providers. For this purpose, ASMAN, an android based application for electronic recording of intrapartum and immediate postpartum care, integrated with Clinical Decision Support, e-partograph, knowledge enhancement and other features was introduced at project sites. The ASMAN application runs on a tablet stationed in several important areas of the health facilities, including registration, triage, the labor room, postpartum areas, operation theatre and post-operative wards.

The ASMAN application had the following components:

- Case management: Digitized case sheet from admission until discharge with integrated clinical rules (admission notes, e-partogram, Safe Childbirth 
Checklist, delivery notes, post-delivery monitoring, post-natal care, discharge slip, referral slip, events section, alerts \& notifications).

- Dashboards and reports: System generated dashboards and reports for respective health facility, district and state level managers.

- E-learning content: All GoI training modules, guidelines and tutorials. Available in audio, video, or readable format in English or in Hindi

- ASMAN Complication Management Game: a casebased game designed to improve management of intrapartum and immediate postpartum/ postnatal complications for developing critical thinking skills of health workers around safe child delivery

- Safe Delivery App: which provides evidence-based clinical guidelines on Basic Emergency Obstetric and Neonatal Care

- Remote support center: staffed $24 / 7$ by senior residents at the medical college for provision of support in cases of unclear management. Staff at the remote support center have access to all cases

ASMAN program implementation took place across 81 public facilities in four districts each in Rajasthan and Madhya Pradesh states of India. The key stakeholders of ASMAN were Governments of Madhya Pradesh and Rajasthan. This project was piloted between June 2017 to May 2020, with support from Reliance Foundation, Tata Trusts, MSD for Mothers, Bill and Melinda Gates Foundation and United States Agency for International Development (USAID). Jhpiego was the lead implementation agency. The respective state governments were consulted to select specific intervention districts that had higher neonatal and maternal mortality rates as compared to the state average, districts without ongoing intervention for improving quality of intrapartum and postpartum care. Within those districts, government health facilities that had a relatively high case load of 50 or more deliveries per month and therefore, greater need for intervention, were selected.

This program implementation offered an opportunity to evaluate the role of a CDSS in improving quality of care during the intrapartum and immediate postpartum periods, assess its impact on delivery outcomes, identification and referral of key maternal and neonatal complications in selected public facilities.

\section{Methodology}

\section{Research aims}

To our knowledge, no studies from India have described the impact of CDSS on clinical outcomes during the intrapartum and immediate postpartum periods. Along with the lack of evidence on effect of CDSS in improving quality of maternity care, this gap represents a crucial research priority for India with global relevance. Through this analysis, we attempt to answer the following questions:

1. What was the uptake of ASMAN application among health care providers?

2. How did the ASMAN application affect adherence to key clinical practices?

3. What was the trend of maternal (pre-eclampsia, eclampsia, postpartum haemorrhage) and neonatal (fresh still births, birth asphyxia) complications during the project implementation?

4. What was the trend of identification and referral of maternal complications (pre-eclampsia, eclampsia, postpartum haemorrhage) during the project implementation?

\section{Study design, and study setting}

We have conducted secondary analysis of program data (government data) collected from 81 public facilities across four districts each in two states of Madhya Pradesh (Jabalpur, Khargone, Ratlam and Vidisha) and Rajasthan (Ajmer, Bhilwara, Kota and Jhalawar). This de-identified dataset was provided by the government of both states. The data collected between August -October 2017 was considered as a baseline and the data collected between December 2019 - March 2020 was considered as a latest assessment. The study was performed in accordance with ethical principles outlined in the World Medical Association (WMA) Declaration of Helsinki [22] where privacy and confidentiality of personal information was assured by getting access to deidentified data.

\section{Study tools and data collection}

The following tools were used to collect data:

- ASMAN application data- has digitized all labour room registers, case sheets, referral and discharge summary forms of Government of India. Every woman who comes to any ASMAN facility for delivery is registered in the application. All forms are filled by the health providers at the 81 project facilities in real time. Details from patient history, labour room case sheets, partograph, until discharge is collected in the ASMAN application. We have used data from ASMAN application to understand filling ratio at admission, delivery, post-delivery, postnatal care (PNC) and discharge. Data of all those women who had delivered at ASMAN facilities and their newborns between November 2017 and March 2020 in Rajasthan and Madhya Pradesh states are used for this analysis. Till March 2020, data of 266,992 women 
who delivered and 228,807 newborns were entered in ASMAN application.

- The observation checklist was developed based on WHO SCC [23] and was approved by GoI as part of monitoring activities under Dakshata program [24]. This checklist was designed to measure adherence to essential practices around childbirth. These practices were divided by pause points: practices that are necessary to perform on admission, just before pushing (or before caesarean), soon after birth $(1 \mathrm{~h})$ and before discharge. This tool was used to explore adherence to practices at the baseline and latest assessment periods. The program officers, with medical background, collected this information; the observation assessment on average took $2-4 \mathrm{~h}$.

- Complication format: Maternal and New Born Complications Identification and Referral Monitoring System. Since, there is no formal mechanism in the government systems to monitor childbirth and new born related complication and management, complication format was introduced by ASMAN program team with the support from the Governments of Madhya Pradesh and Rajasthan. The complication reporting format captured data on key maternal and newborn health indicators from the labour room, postpartum ward, Sick Newborn Care Unit (SNCU), admissions and discharge department of the facility. This format captured data on total deliveries, type of deliveries, fresh stillbirths, preterm births, maternal and neonatal death, maternal complications (pre-eclampsia, eclampsia, sepsis, postpartum haemorrhage, sepsis), neonatal complications (neonatal asphyxia and sepsis), refer in and refer out data for maternal and neonatal complications. One nodal person, preferably a labour room staff, was selected from each intervention facility to act as the key contact person for this initiative and was validated regularly by ASMAN program team. This tool was used to explore effect of ASMAN application on delivery outcomes.

\section{Data analysis}

To describe uptake of ASMAN application, we computed the filling rates of 75 key data fields of the application and analysed the differences by pause points, level of health facility and average annual delivery load at the health facilities.

To analyze the change in adherence to evidence based practices after roll out of the intervention, we combined the baseline assessment and last periodic assessment data sets. For overall univariate analysis of adherence to key clinical practices before and after comparison, we computed means for before and latest intervention periods and compared them using chi square test. For adherence to evidence based practices, we also performed multivariable logistic regression analysis for each practice while adjusting for level of facility, average delivery load at the facility and availability of resources required for each key practice.

To analyze trends in maternal and neonatal complications, and referrals we utilized the monthly complication format data which was shared by all ASMAN intervention facilities. As the intervention was rolled out in a staggered manner at different time points across project health facilities, we categorized the complication data of each facility into two time periods corresponding to before and after intervention roll out.

Within each time period, we further grouped monthly data into quarterly data (3 months' data), such that each quarter represented a time interval relative to the intervention roll out. For example, $\mathrm{Q}-1$ and $\mathrm{Q}+1$ denoted the periods corresponding to 3 months before and 3 months after intervention rollout respectively. The month of intervention roll out together with subsequent 2 months were denoted as Q0 or quarter 0 or the time interval corresponding to intervention roll out. Data of corresponding quarters was combined for all facilities and this dataset was used for generating simple time series plots (line/bar) for analysing the trends before and after intervention roll out.

Single group interrupted time series regression analysis was performed on two dependent variables 1 ) fresh still birth rate and 2) incidence of neonatal asphyxia. We have conducted interrupted time series analysis for these two outcomes as these were primary outcomes of the intervention. Monthly data was utilized for carrying out this analysis, yielding data for 12 time points before and after intervention roll out respectively ( $\mathrm{M}-12$ to $\mathrm{M}-1$ before roll out and $M+1$ to $M+12$ after roll out). Coefficients or parameters which represented a shift in the level (intercept) of the dependent variable and a shift in the rate of change (slope) of dependent variable, after intervention, were computed along with $95 \%$ confidence intervals. Newey west standard errors were utilized to account for autocorrelation.

For all statistical tests of significance, $p$ value $<0.05$ was considered significant. We used Statistics package for the Social Sciences (SPSS), version 24, Stata version 14 and Microsoft Excel, for data analysis.

\section{Results}

\section{Characteristics of facilities}

Sixty-three percent of 81 intervention facilities were community health centres. More than half of intervention facilities had average monthly delivery load less than 100 (Table 1). 
Table 1 Characteristics of ASMAN facilities

\begin{tabular}{lll}
\hline Characteristics & Total number & Percent \\
\hline Facility type & & \\
District Hospital & $\mathbf{6}$ & 7.4 \\
Sub-divisional (district) Hospitals & $\mathbf{1 1}$ & 13.6 \\
Satellite hospital & $\mathbf{1}$ & 1.2 \\
Community Health Centre & $\mathbf{5 1}$ & 63.0 \\
Primary Health Centre & $\mathbf{1 2}$ & 14.8 \\
Monthly delivery load & & \\
Less than 100 & $\mathbf{4 1}$ & 50.6 \\
100-200 & $\mathbf{2 7}$ & 33.3 \\
201-300 & $\mathbf{5}$ & 6.2 \\
Above 300 & $\mathbf{8}$ & 9.9 \\
Total & $\mathbf{8 1}$ & $\mathbf{1 0 0}$ \\
\hline
\end{tabular}

\section{Uptake of ASMAN application}

The analysis of filling ratio of ASMAN application revealed that filling ratio was lowest at the PNC period (40.5\%), followed by admission (80.2\%), discharge (82.9\%), post-delivery (93.1\%) and delivery (93.7\%) (Table 3). Further, it was also found that filling ratio was low in high delivery load facilities compare to low and medium delivery load facilities (Table 2). However, filling ratio was not statistically significant by facility type and by delivery load.

\section{Adherence to key clinical practices}

Table 3 illustrates providers' adherence to key clinical practices across all pause points at the baseline and latest assessment. In univariate analysis, statistically significant improvement in adherence to key clinical practices was observed in 18 of 20 key clinical practices.
Measuring birth weight and breastfeeding initiation were the only practices that did not show statistically significant change in univariate analysis; both of these practices were above $70 \%$ at the time of baseline assessment. However, after adjusting for level of facility, average annual delivery load and resource availability all clinical practices showed significant improvement (Table $3)$.

\section{Delivery outcomes}

Figure 1 depicts the trend of fresh still birth rates in intervention facilities through the study period. There was a steady decline through the period and the difference between mean still birth rate of four quarters before intervention roll out and four quarters after intervention roll out, was statistically significant $(p<0.05)$.

The interrupted time series regression analysis on monthly data revealed that there was a decrease in fresh still birth rate after intervention roll out [-0.92 (95\% confidence interval: $-3.00-1.1 .4)$ ], though this change was not statistically significant. The trend over time did not change significantly either [0.12 ( $95 \%$ confidence interval: $-0.13-0.38$ )] (supplementary file 1 ).

Figure 2 depicts the trend of neonatal asphyxia cases (per 1000 live births) in intervention facilities through the study period. There is a clear decline observed in number of cases after ASMAN application roll out. The difference between the mean number of cases in time periods before and after application rollout, found to be statistically significant $(p<0.05)$.

The interrupted time series regression analysis on monthly data revealed that there was a decrease in number of neonatal asphyxia cases after intervention roll out [- 3.12 (95\% confidence interval: $-9.73-3.47)]$, though

Table 2 Filling Ratio of key indicators at different pause points by facility type and delivery load

\begin{tabular}{|c|c|c|c|c|c|c|}
\hline \multicolumn{7}{|l|}{ By facility type } \\
\hline Facility Type & Admission & Delivery & Post delivery & PNC & Discharge & $P$ value \\
\hline District Hospital $(n=6)$ & $69.8 \%$ & $91.1 \%$ & $88.3 \%$ & $23.2 \%$ & $82.4 \%$ & \multirow[t]{6}{*}{0.08} \\
\hline Sub-divisional (district) Hospitals $(n=11)$ & $84.6 \%$ & $95.1 \%$ & $93.0 \%$ & $42.4 \%$ & $83.3 \%$ & \\
\hline Satellite Hospital $(n=1)$ & $92.0 \%$ & $97.5 \%$ & $96.5 \%$ & $74.7 \%$ & $89.1 \%$ & \\
\hline Community Health Centre $(n=51)$ & $87.3 \%$ & $95.3 \%$ & $97.2 \%$ & $50.7 \%$ & $82.2 \%$ & \\
\hline Primary Health Centre $(N=12)$ & $90.7 \%$ & $96.1 \%$ & $98.6 \%$ & $73.3 \%$ & $86.5 \%$ & \\
\hline Grand Total $(N=81)$ & $80.2 \%$ & $93.7 \%$ & $93.1 \%$ & $40.5 \%$ & $82.9 \%$ & \\
\hline \multicolumn{7}{|l|}{ By delivery load } \\
\hline Delivery load & Admission & Delivery & Post delivery & PNC & Discharge & $P$ value \\
\hline Less than $100(n=41)$ & $91.0 \%$ & $96.0 \%$ & $97.3 \%$ & $68.5 \%$ & $84.9 \%$ & \multirow[t]{5}{*}{0.05} \\
\hline $100-200(n=27)$ & $87.8 \%$ & $95.1 \%$ & $97.7 \%$ & $51.4 \%$ & $82.6 \%$ & \\
\hline $201-300(n=5)$ & $85.4 \%$ & $96.5 \%$ & $97.9 \%$ & $47.4 \%$ & $87.2 \%$ & \\
\hline above $300(n=8)$ & $70.3 \%$ & $91.3 \%$ & $87.7 \%$ & $20.9 \%$ & $81.3 \%$ & \\
\hline Grand Total $(n=81)$ & $80.2 \%$ & $93.7 \%$ & $93.1 \%$ & $40.5 \%$ & $82.9 \%$ & \\
\hline
\end{tabular}


Table 3 Univariate and multivariate analysis of providers' adherence to key clinical practices (\%)

\begin{tabular}{|c|c|c|c|c|}
\hline Practices & $\begin{array}{l}\text { Baseline (August - } \\
\text { October 2017) }\end{array}$ & $\begin{array}{l}\text { Latest (December } 2019 \text { - } \\
\text { March 2020) }\end{array}$ & $\begin{array}{l}p \text {-value } \\
\text { (univariate } \\
\text { analysis) }\end{array}$ & $\begin{array}{l}p \text { value } \\
\text { (multivariate }^{a} \\
\text { analysis) }\end{array}$ \\
\hline \multicolumn{5}{|l|}{ On admission } \\
\hline Records fetal heart rate at admission & 46 & 96 & 0.004 & $<0.001$ \\
\hline Records mother's BP at admission & 46 & 93 & 0.007 & $<0.001$ \\
\hline $\begin{array}{l}\text { Conducts PV examination only as indicated ( } 4 \text { hourly or } \\
\text { based) on clinical indication }\end{array}$ & 32 & 90 & $<0.001$ & $<0.001$ \\
\hline Performs hand hygiene & 43 & 89 & 0.007 & $<0.001$ \\
\hline $\begin{array}{l}\text { Provider identifies and manages severe Pre-eclampsia/ } \\
\text { Eclampsia }\end{array}$ & 2 & 60 & $<0.001$ & $<0.001$ \\
\hline $\begin{array}{l}\text { Initiates Partograph plotting once the } C x \text { dilation is }>= \\
4 \mathrm{~cm}\end{array}$ & 27 & 81 & $<0.001$ & $<0.001$ \\
\hline $\begin{array}{l}\text { Provider interprets partograph correctly and adjusts care } \\
\text { according to findings }\end{array}$ & 15 & 51 & $<0.001$ & $<0.001$ \\
\hline \multicolumn{5}{|l|}{ Just before pushing or at caesarean section } \\
\hline Preforms hand hygiene & 49 & 96 & 0.002 & $<0.001$ \\
\hline Oxytocin within one minute of delivery of baby & 59 & 96 & 0.05 & $<0.001$ \\
\hline Immediate newborn care & 0 & 74 & $<0.001$ & $<0.001$ \\
\hline \multicolumn{5}{|l|}{ Soon after delivery (within $1 \mathrm{~h}$ ) } \\
\hline Delivers the baby on mother's abdomen & 42 & 95 & 0.002 & $<0.001$ \\
\hline Thermal management of newborn & 15 & 84 & $<0.001$ & $<0.001$ \\
\hline Weighs the baby & 88 & 99 & 0.67 & 0.048 \\
\hline Initiates breast feeding within one hour of birth & 70 & 99 & 0.18 & 0.001 \\
\hline $\begin{array}{l}\text { Provider identifies and manages Post-Partum } \\
\text { Haemorrhage }\end{array}$ & 4 & 59 & $<0.001$ & $<0.001$ \\
\hline Measures baby's temperature & 19 & 48 & 0.006 & 0.021 \\
\hline Records mother's temperature & 12 & 48 & $<0.001$ & 0.002 \\
\hline \multicolumn{5}{|l|}{ At the time of discharge } \\
\hline $\begin{array}{l}\text { Counsels on danger signs to mother at time of } \\
\text { discharge }\end{array}$ & 26 & 65 & 0.002 & $<0.001$ \\
\hline $\begin{array}{l}\text { Counsels on post-partum family planning to mother at } \\
\text { discharge }\end{array}$ & 43 & 98 & 0.001 & $<0.001$ \\
\hline $\begin{array}{l}\text { Counsels on exclusive breast feeding to mother at } \\
\text { discharge }\end{array}$ & 59 & 83 & 0.001 & 0.001 \\
\hline
\end{tabular}

after adjusting for level of facility, average annual delivery load and resource availability for respective practice

this change was not statistically significant. The rate of decline (slope) increased [- 0.36 (95\% confidence interval: $-1.09-0.36)$, though this too was not statistically significant (Additional file 1).

\section{Maternal complications}

Figure 3 illustrates the trend of pre -eclampsia /eclampsia cases and refer out in intervention sites before and after ASMAN application rollout. There is an increase in identification of pre-eclampsia and eclampsia cases after application roll-out, while referral out declined over the same time period.

Analysis of postpartum haemorrhage cases and refer out trends in intervention sites before and after ASMAN application rollout revealed an increase in identification of postpartum haemorrhage cases and decrease in referral out (Fig. 4).

\section{Discussion}

Our study described the uptake of ASMAN application among health care providers, the role of ASMAN application in improving adherence to key clinical practices, delivery outcomes and maternal complications. We have observed that, introducing ASMAN application resulted in statistically significant improvements in adherence to key clinical practices. However, overall completeness of case sheets in ASMAN application was low across all levels of facilities. We have observed reduction in fresh 


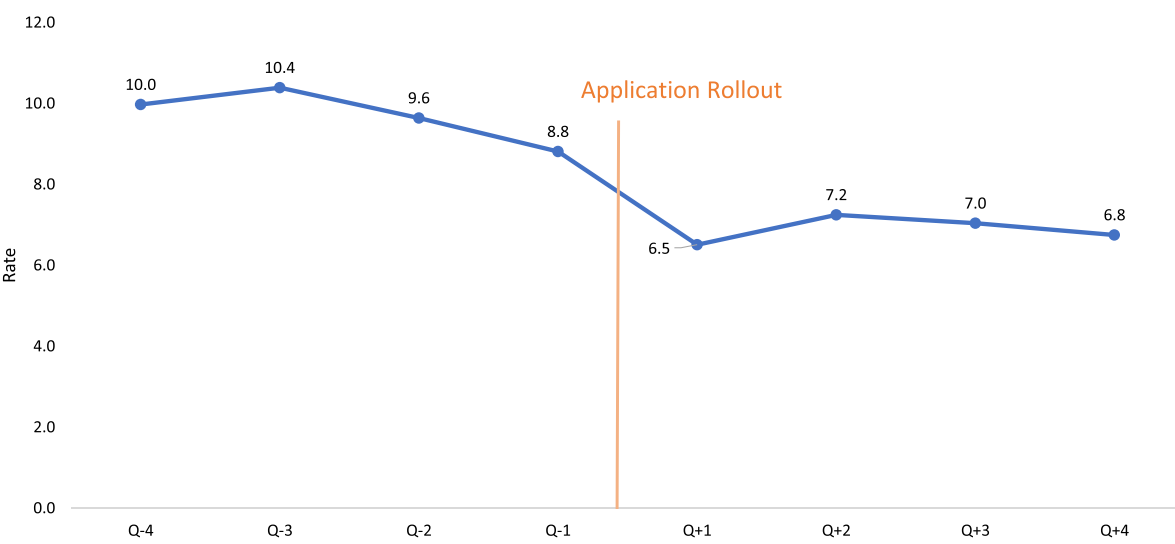

Fig. 1 Trend of stillbirth rate (per 1000 live births) before and after roll out of ASMAN application

still birth rates and asphyxia, but these results were not statistically significant in interrupted time series analysis. On the other hand, our analysis showed that identification of maternal complications has increased over the period of program implementation and at the same time referral outs decreased.

\section{Uptake of ASMAN application}

We have included completeness of case sheets in application as a measure of data quality as it is a commonly assessed dimension of data quality mentioned in a review [25]. Although, using medical records has been criticized for measuring quality of record keeping practices instead of quality of care, it was argued that patient case records should be part of quality of care assessment; because individual case records are essential not only for case management and peer review but also for assessing the impact of health interventions [26]. Additionally, it was noted that clinical record keeping enables continuity of care and improves communication between different health providers [27].
Our results indicated that the filling ratio during the post-partum period was low across all type of facilities. The poor clinical documentation was reported in a review of obstetric records conducted in India [28], with the extent of documentation varying between 1.3\% (assessment of mother's condition at the discharge) and 99.1\% (admission date). Similarly, a multicenter retrospective review of clinical records of cesarean delivery in five low-income countries identified poor-quality record keeping with missing information on key events, management of complications, and delivery outcomes [29]. Furthermore, we have found that the filling ratio across all pause points was low at the district hospital level and high delivery load facilities. In our qualitative study [30], health care providers mentioned that staff shortage, patient urgency, high caseloads prevented staff to complete all fields in the application. According to a study conducted by Chaturvedi [28] and colleagues, Madhya Pradesh state of India, documentation was better at district hospitals due to higher qualification of the staff in those facilities and availability of forms at the district hospitals. Although, the present study did not conduct

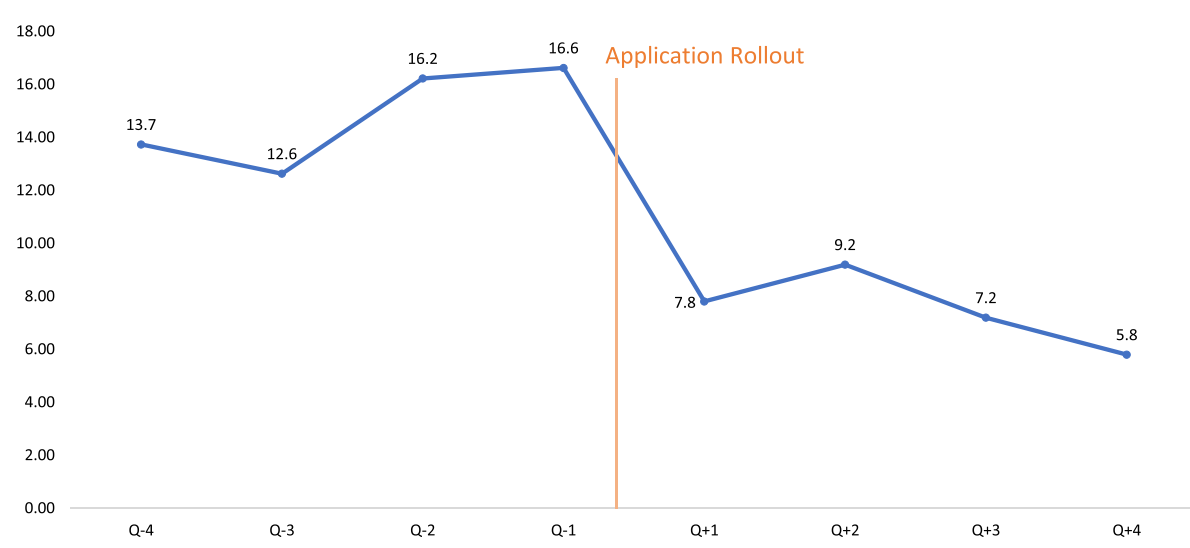

Fig. 2 Trend of neonatal asphyxia cases (per 1000 live births) before and after roll out of ASMAN application 


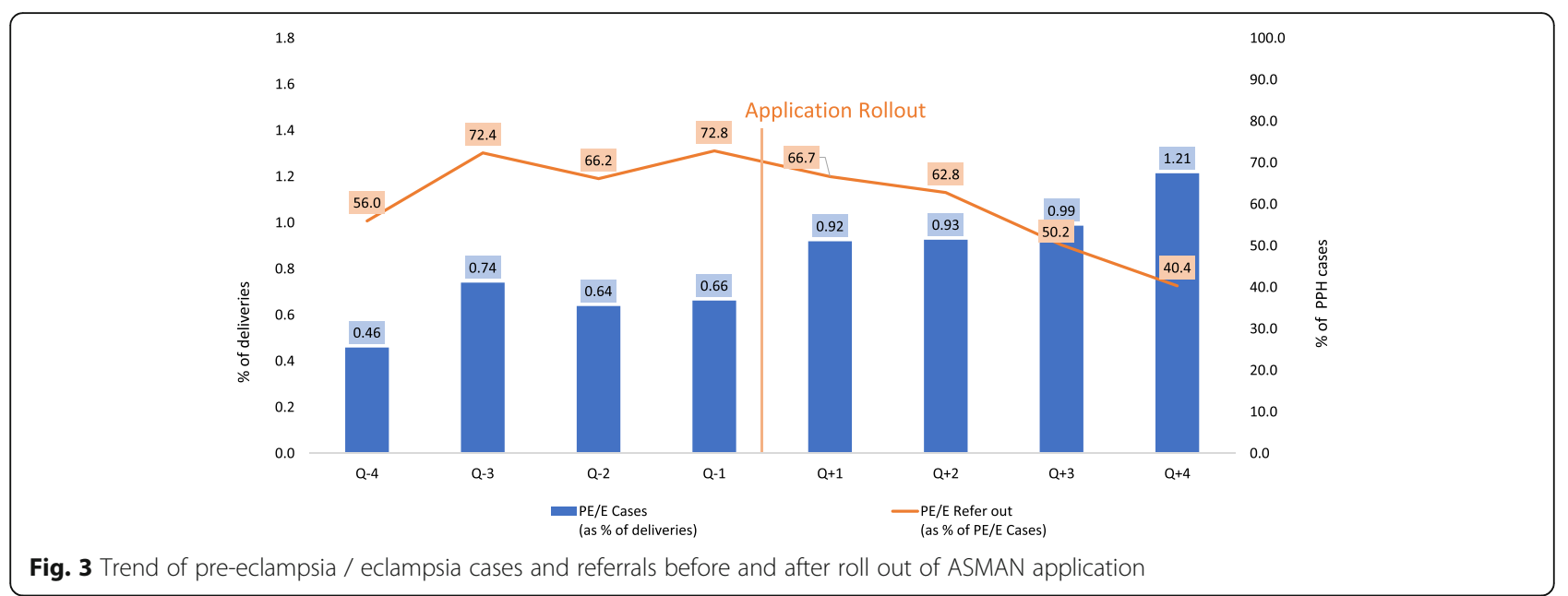

comparison of documentation before and after ASMAN application roll out, due to the unavailability of data before application rollout, respondents in our qualitative study [30] reported that ASMAN application improved documentation. Additionally, a study conducted in Australian tertiary maternity facility [31] found that the use of electronic health records resulted in significant improvements in completeness of data captured. Furthermore, it was noted by the same study that the data captured electronically was easily available to providers compare to paper based records. Understanding the reasons for the low filling ratios at the PNC period would require further research. The low filling ratio at facilities with delivery load more than 300 could be explained by bigger client -provider ratio could be reasons as per anecdotal experience.

\section{Adherence to key clinical practices}

Our study revealed that quality of care across all pause points improved during the implementation of ASMAN application. Furthermore, labor room staff in the qualitative study mentioned that ASMAN application improved their ability to take a complete history and physical exam, identify high-risk patients, manage cases confidently, facilitate provider communication, improve reporting processes, and ensure continuity of care for referral patients [30]. In our study we have observed that examinations around identification and management of complications, initiation of partograph, identification of post-partum haemorrhage increased significantly. These results indicate that ASMAN application has the potential to improve quality of care provided around the childbirth. These are very encouraging results, as timely identification of complications is crucial because over a third of maternal deaths, a significant proportion of pregnancy-related life-threatening conditions; approximately half of all stillbirths and a quarter of neonatal deaths are attributed to complications that occur during labour, childbirth or the immediate postpartum period [32-34]. Our findings are in line with the results of three systematic reviews on the role of CDSS use on providers' adherence to clinical practices [12-14]. According to

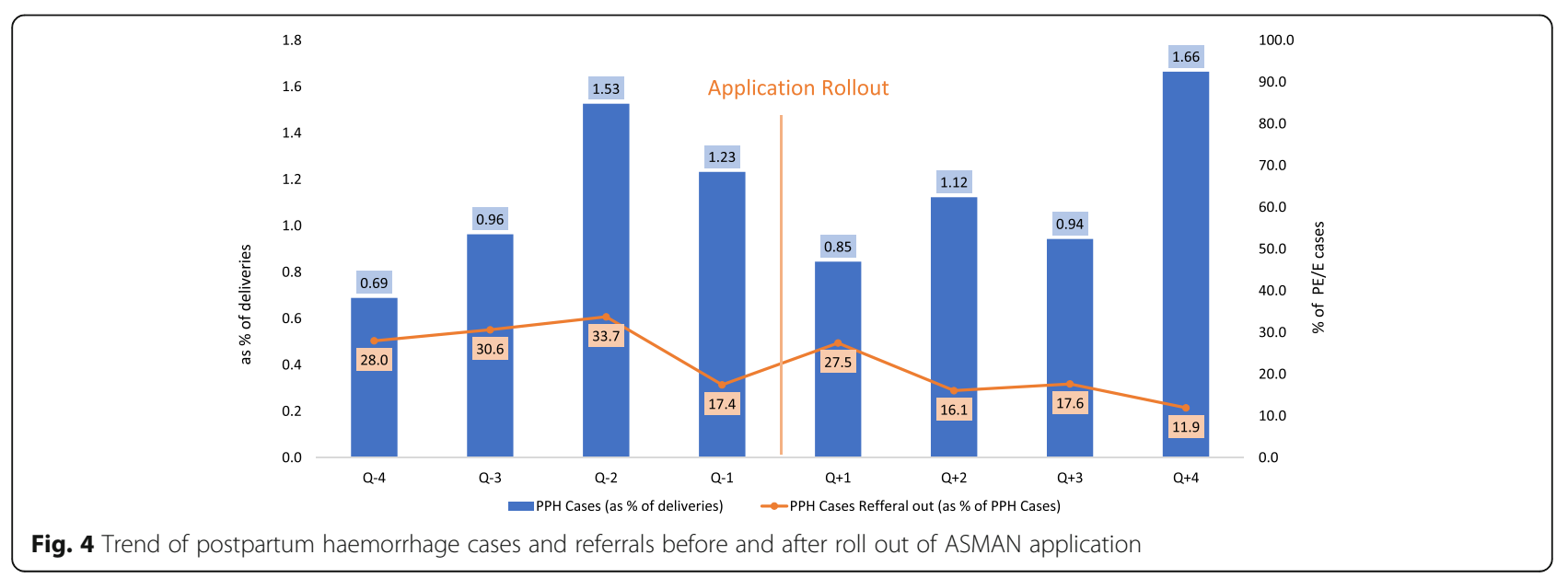


Garg and colleagues [12], better performance of providers was observed in studies where users were automatically prompted to use the systems compared with studies in which users were required to actively initiate the system. Additionally, the same review observed better performance in studies in which the trial authors also developed the CDSS software [12]. Moreover, a synthesis of high quality systematic reviews [14] showed that the positive effect of CDSS depends on the services which it was used; CDSS positively impacted providers' performance in studies on drugs ordering and preventive care measures. Kawamoto et al., [13] identified four features strongly associated with a decision support system's ability to improve clinical practice-(a) decision support provided automatically as part of clinician workflow, (b) decision support delivered at the time and location of decision making, (c) actionable recommendations provided, and (d) computer based. Additionally, CDSS should also provide periodic performance feedback, request documentation of the reason for not following system recommendations, and share decision support results with patients.

While there are studies on benefits of CDSS in general, there is very limited research on benefits of CDCC in maternity care. Duysburgh et al., [19] did not find a significant improvement in quality of antenatal and delivery care with the use of CDSS assessed in Burkina Faso, Ghana and Tanzania. They have concluded that, history taking, counselling, health education, laboratory investigations, and examination and monitoring of mothers and newborns during childbirth were not performed according to the standards. A study conducted in South Africa for improving compliance of health care workers with antenatal care guidelines found overall improvement, but it was not statistically significant [20]. McNabb et al., reports significant improvement in health counselling, technical services, quality of health education and patient satisfaction as a result of a mobile phone decision support during antenatal care in Nigeria [21].

Furthermore, studies conducted in India on the role of CDSS in the management of cardiovascular diseases [35] and hypertension [36] demonstrated positive role of CDSS in improving care, adherence to guidelines, counselling and follow up with patients that resulted in blood pressure reduction.

\section{Delivery outcomes and maternal complications}

Improved practices around childbirth have a potential to prevent birth asphyxia and complications due to prematurity, which are some of the main causes of fresh still births and early neonatal deaths [34, 34, 37]. Our results revealed that there was a significant decrease in fresh still birth and asphyxia, however this decrease wasn't statistically significant in interrupted time series analysis. These results are in line with the global evidence on the lack of evidence of potential impact of CDSS on patient outcomes [12-14, 37, 38]. Thus, according to the systematic review, majority of the studies assessed patient outcomes often without adequate statistical power to detect clinically important differences [12]. Jaspers and colleagues found only few studies on impact of CDSS on patient outcomes, though many of these have been too small in sample size or too short in time to reveal clinically important effect [14]. Furthermore, a systematic review and meta-analysis found that CDSS linked to electronic health records did not detect statistically significant reduction in morbidity and mortality [38].

The lack of statistically significant improvement in delivery outcomes could be attributed to the small sample size and short follow-up periods which is not long enough to assess the impact of CDSS on patient outcomes [14].

During the course of the program implementation, we have observed that identification of pre-eclampsia is increased while referrals for the same conditions decreased. This change could be attributed to the improved assessment at the time of admission. Moreover, we have observed the same trend in identification and referral of postpartum hemorrhage that could be explained by increased administration of oxytocin within 1 min of delivery.

\section{Strengths and limitations}

The results of our study contributes to the dearth of literature on the role of CDSS in maternity care. From the onset of the program our team trained and worked closely with the focal point in each facility to ensure quality of data and timely reporting. Furthermore, as a part of program implementation, all providers were trained in distinguishing and reporting fresh still births. Additionally, data reported from facilities were regularly validated by our team. The availability of data before and during the program implementation allowed us to estimate the role of CDSS in improving quality of intrapartum care and delivery outcomes. Our study has few limitations. Firstly, it is possible that providers carried out the patient management according to the standards but didn't record it in application. Secondly, our assessment involved direct observation of provider practices, as a result potential Hawthorne effect would have happened. To minimize Hawthorne effect we trained our project officers using standard observation checklist and standard operating procedures. Lastly, due to utilization of program data in our analysis, establishing causal claim is limited. 


\section{Conclusion}

To our knowledge, this is the first study that provides and evidence on the role of technology to improve the quality of intrapartum care and delivery outcomes in India. However, the results of this study could be generalized to another country with similar settings. Our study indicates CDSS has a potential to improve quality of intrapartum care and delivery outcome. Future studies with rigorous study design are required to understand the impact of technology in improving quality of maternity care. These studies could provide evidence on reducing the burden of maternal and neonatal death attributable to inadequate quality of care in India and globally.

\begin{abstract}
Abbreviations
ANM: Auxiliary Nursing Midwife; ASMAN: The Alliance for Saving Mothers and Newborns; CDSS: Computerized clinical decision support; Gol: Government of India; MO: Medical Officer; MSD: MSD for Mothers; OT: Operation theatre; PNC: Postnatal Care; SNCU: Sick Newborn Care Unit; SCC: Safe Childbirth Checklist; SPSS: Statistical Package for the Social Sciences; USAID: United States Agency for International Development
\end{abstract}

\section{Supplementary Information}

The online version contains supplementary material available at https://doi. org/10.1186/s12884-021-03710-y.

Additional file 1. Interrupted time series analysis on fresh still birth rates and incidence of neonatal asphyxia at intervention facilities.

\section{Acknowledgments \\ ASMAN program is designed, executed, and funded by 5 development partners-, Bill and Melinda Gates Foundation, MSD for Mothers, Reliance Foundation, Tata Trusts, and USAID. We sincerely thank the Project Management Unit, involved in driving the program interventions and both state governments for their continuous support and suggestions. We would also like to acknowledge the support provided by the implementing partners - Avalon, Sambodhi and Bodhi, without whom this project and the study would not have been possible. We would like to acknowledge Young Mi Kim and Rachel Haws for reviewing the manuscript and providing valuable suggestions. We also thank the reviewers of this manuscript who helped to improve it with their comments and suggestions.}

\section{Authors' contributions}

RW, PS, NB, PG, BS, KL, GU, TC, AM, BS conceptualization of project. GU, KL, BS leading manuscript drafting. GU, AS, DB, AB, CSJ, RD drafting study protocol, development of tools, manuscript drafting. YJ, MA, JB, RD overseeing project implementation, development of tools, drafting manuscript. AS, DB, CSJ, AB data compilation, cleaning, analysis. GU, KL, BS, RW, PS, NB, PG, AS, TC, AM, BS conceptualization, reviewing and guiding analysis and manuscript. All authors read and approved the final version of the manuscript.

\section{Funding}

The program was designed, supported and funded by the Alliance for Saving Mothers and Newborns (ASMAN), with support from the Reliance Foundation, Tata Trusts, MSD* for Mothers, The Bill \& Melinda Gates Foundation, and the United States Agency for International Development (USAID).

*- This program was funded by, developed with and is being implemented in collaboration with MSD for Mothers, MSD's \$500 million initiative to help create a world where no woman has to die while giving life. MSD for Mothers is an initiative of Merck \& Co., Inc., Kenilworth, NJ, U.S.A.

\section{Availability of data and materials}

Qualified researchers may request data access by emailing the corresponding author. In such an event, the researchers will consult with the Government of Rajasthan and Madhya Pradesh state health departments before providing data access to the concerned parties.

\section{Declarations}

\section{Ethics approval and consent to participate}

This study was reviewed and approved by the Government of Rajasthan and the Government of Madhya Pradesh, which own the data and provided the datasets. The Johns Hopkins School of Public Health Institutional Review Board (IRB) reviewed the activities and determined them to be not human subjects research and thus not requiring IRB oversight (IRB No: 12705). The Johns Hopkins School of Public Health IRB is one of Jhpiego's designated IRBs of record as documented with the U.S. government's office of human subject's protection. All data used in this study were collected as a part of routine monitoring of government programs, and the datasets provided by the Governments of Rajasthan and Madhya Pradesh did not contain any patient or provider identifiers; hence informed consent was not required.

\section{Consent for publication}

Not applicable.

\section{Competing interests}

The authors declare that they have no competing interests.

\section{Author details}

1Jhpiego-An Affiliate of Johns Hopkins University, New Delhi 110020, India. ${ }^{2}$ Department of Health and Family Welfare, NHM, Jaipur, Rajasthan 302001, India. ${ }^{3}$ Maternal Health, NHM, Bhopal, Madhya Pradesh 462011, India. ${ }^{4}$ Project Management Unit, ASMAN: Alliance for Saving Mothers and Newborns, Mumbai 400021, India. ${ }^{5}$ MSD for Mothers, Mumbai 4000098, India. ${ }^{6}$ Reliance Foundation, Mumbai 400021, India. ${ }^{7}$ Tata Trusts, Mumbai 400005, India.

Received: 13 November 2020 Accepted: 9 March 2021

Published online: 07 April 2021

\section{References}

1. Bhutta ZA, Das JK, Bahl R, Lawn JE, Salam RA, Paul VK, Sankar MJ, Blencowe H, Rizvi A, Chou VB, Walker N, Lancet Newborn Interventions Review Group; Lancet Every Newborn Study Group. Can available interventions end preventable deaths in mothers, newborn babies, and stillbirths, and at what cost? Lancet. 2014;384(9940):347-70. https://doi. org/10.1016/S0140-6736(14)60792-3.

2. Tunçalp Ö, Were WM, MacLennan C, Oladapo OT, Gülmezoglu AM, Bahl R, Daelmans B, Mathai M, Say L, Kristensen F, Temmerman M, Bustreo F. Quality of care for pregnant women and newborns-the WHO vision. BJOG. 2015;122(8):1045-9. https://doi.org/10.1111/1471-0528.13451.

3. Joe W, Perkins JM, Kumar S, Rajpal S, Subramanian SV. Institutional delivery in India, 2004-14: unravelling the equity-enhancing contributions of the public sector. Health Policy Plan. 2018;33(5):645-53. https://doi.org/10.1093/ heapol/czy029.

4. Lim SS, Dandona L, Hoisington JA, James SL, Hogan MC, Gakidou E. India's Janani Suraksha Yojana, a conditional cash transfer programme to increase births in health facilities: an impact evaluation. Lancet. 2010;375(9730):200923. https://doi.org/10.1016/S0140-6736(10)60744-1.

5. Chaturvedi S, De Costa A, Raven J. Does the Janani Suraksha Yojana cash transfer programme to promote facility births in India ensure skilled birth attendance? A qualitative study of intrapartum care in Madhya Pradesh. Global Health Act. 2015;8(1):1. https://doi.org/10.3402/gha.v8.27427.

6. Sharma J, Leslie HH, Regan M, Nambiar D, Kruk ME. Can India's primary care facilities deliver? A cross-sectional assessment of the Indian public health system's capacity for basic delivery and newborn services. BMJ Open. 2018; 8(6):e020532. https://doi.org/10.1136/bmjopen-2017-020532.

7. Maternal Health Division Ministry of Health and Family Welfare Government of India. DAKSHATA Empowering Providers for Improved MNH Care during Institutional Deliveries April 2015 A strategic initiative to strengthen quality of intra- and immediate postpartum care. Retrieved from URL https://nhm. gov.in/WriteReadData//892s/81164783601523441220.pdf. Accessed 30 Sept 2020 
8. Kumar S, Yadav V, Balasubramaniam S, Jain Y, Joshi CS, Saran K, Sood B. Effectiveness of the WHO SCC on improving adherence to essential practices during childbirth, in resource constrained settings. BMC Pregnancy Childbirth. 2016;16(1):345. https://doi.org/10.1186/s12884-016-1139-x.

9. Semrau K, Hirschhorn LR, Delaney MM, Singh VP, Saurastri R, Sharma N, Tuller DE, Firestone R, Lipsitz S, Dhingra-Kumar N, Kodkany BS, Kumar V, Gawande AA, Better Birth Trial Group. Outcomes of a Coaching-Based WHO Safe Childbirth Checklist Program in India. New Engl J Med. 2017;377(24): 2313-24. https://doi.org/10.1056/NEJMoa1701075.

10. Spector JM, Agrawal P, Kodkany B, Lipsitz S, Lashoher A, Dziekan G, Bahl R, Merialdi M, Mathai M, Lemer C, Gawande AA. Improving quality of care for maternal and newborn health: prospective pilot study of the who safe childbirth checklist program. PLoS One. 2012;7(5):e35151. https://doi.org/1 0.1371/journal.pone.0035151.

11. Varghese B, Copas A, Kumari S, Bandyopadhyay S, Sharma J, Somen S, Yadav V, Kumar S. Does the safe childbirth checklist (SCC) program save newborn lives? Evidence from a realistic quasi-experimental study, Rajasthan, India. Matern Health Neonatol Perinatol. 2019;5(1):3. https://doi. org/10.1186/s40748-019-0098-4

12. Garg AX, Adhikari NK, McDonald H, Rosas-Arellano MP, Devereaux PJ, Beyene J, Sam J, Haynes RB. Effects of computerized clinical decision support systems on practitioner performance and patient outcomes: a systematic review. JAMA. 2005;293(10):1223-38. https://doi.org/10.1001/ja ma.293.10.1223.

13. Kawamoto K, Houlihan CA, Balas EA, Lobach DF. Improving clinical practice using clinical decision support systems: a systematic review of trials to identify features critical to success. BMJ. 2005;330(7494):765. https://doi. org/10.1136/bmj.38398.500764.8F.

14. Jaspers MW, Smeulers M, Vermeulen H, Peute LW. Effects of clinical decision-support systems on practitioner performance and patient outcomes: a synthesis of high-quality systematic review findings. J Am Med Inform Assoc. 2011;18(3):27-334. https://doi.org/10.1136/amia jnl-2011-000094.

15. Bright TJ, Wong A, Dhurjati R, Bristow E, Bastian L, Coeytaux RR, Samsa G, Hasselblad V, Williams JW, Musty MD, Wing L, Kendrick AS, Sanders GD, Lobach D. Effect of clinical decision support systems: a systematic review. Ann Intern Med. 2012;157(1):29-43. https://doi.org/10.7326/0003-4819-1 57-1-201207030-00450

16. Roshanov PS, Fernandes N, Wilczynski JM, Hemens BJ, You JJ, Handler SM, Nieuwlaat R, Souza NM, Beyene J, Van Spall HGC, Garg AX, Haynes RB. Features of effective computerised clinical decision support systems: metaregression of 162 randomised trials. BMJ. 2013;346(feb14 1):f657. https://doi. org/10.1136/bmj.f657.

17. Souza NM, Sebaldt RJ, Mackay JA, Prorok JC, Weise-Kelly L, Navarro T, Wilczynski NL, Haynes RB. Computerized clinical decision support systems for primary preventive care: a decision-maker-researcher partnership systematic review of effects on process of care and patient outcomes. Implement Sci. 2011;6(1):87. https://doi.org/10.1186/1748-5908-6-87.

18. Sutton RT, Pincock D, Baumgart DC, Sadoski DC, Fedorak RN, Kroeker KI. An overview of clinical decision support systems: benefits, risks, and strategies for success. NPJ Digit Med. 2020;3(17). https://doi.org/10.1038/s41746-0200221-y.

19. Duysburgh E, Temmerman M, Ye M, Williams A, Massawe S, Williams J, Mpembeni R, Loukanova S, Haefeli WE, Blank A. Quality of antenatal and childbirth care in rural health facilities in Burkina Faso, Ghana and Tanzania: an intervention study. Trop Med Int Health. 2016;21(1):70-83. https://doi. org/10.1111/tmi.12627

20. Horner V, Rautenbach P, Mbananga N, Mashamba T, Kwinda H. An e-health decision support system for improving compliance of health workers to the maternity care protocols in South Africa. Appl Clin Inform. 2013;4(1):25-36. https://doi.org/10.4338/ACl-2012-10-RA-0044.

21. McNabb M, Chukwu E, Ojo O, Shekhar N, Gill CJ, Salami H, Jega F. Assessment of the quality of antenatal care services provided by health workers using a mobile phone decision support application in northern Nigeria: a pre/post-intervention study. PLoS One. 2015;10(5):e0123940. https://doi.org/10.1371/journal.pone.0123940.

22. World Medical Association. Declaration of Helsinki. 1974.

23. WHO. Safe Childbirth Checklist Implementation Guide Improving the quality of facility-based delivery for mothers and newborns, 2015. Retrieved from URL https://apps.who.int/iris/bitstream/handle/10665/199177/97892415494 55_eng.pdf? sequence=1. Accessed 10 Aug 2020.
24. Government of India. Ministry of Health and Family Welfare. National Health Mission. Dakshata Implementation package. Retrieved from URL https:// nhm.gov.in/index 1. php?lang=1\&level=3\&sublinkid=838\&lid=449. Accessed 10 Aug 2020.

25. Weiskopf NG, Weng C. Methods and dimensions of electronic health record data quality assessment: enabling reuse for clinical research. J Am Med Inform Assoc. 2013;20(1):144-51. https://doi.org/10.1136/amiajnl-2011000681.

26. Hulton LA, Matthews Z, Stones RW. A framework for the evaluation of quality of care in maternity services. Southampton: University of Southampton; 2000. Retrieved from URL https://assets.publishing.service. gov.uk/media/57a08d7fe5274a27b200189d/HOppsMonographEvalMa ternityServices.pdf. Accessed 10 Aug 2020.

27. Mathioudakis A, Rousalova I, Gagnat AA, Saad N, Hardavella G. How to keep good clinical records. Breathe. 2016;12(4):369-73. https://doi.org/10.1183/2 0734735.018016

28. Chaturvedi S, Randive B, Raven J, Diwan V, De Costa A. Assessment of the quality of clinical documentation in India's JSY cash transfer program for facility births in Madhya Pradesh. Int J Gynecol Obstet. 2016;132(2):17983. https://doi.org/10.1016/j.jjgo.2015.07.016.

29. Landry E, Pett C, Fiorentino R, Ruminjo J, Mattison C. Assessing the quality of record keeping for cesarean deliveries: results from a multicenter retrospective record review in five low-income countries. BMC Pregnancy Childbirth. 2014;14(1):139. https://doi.org/10.1186/1471-2393-14-139.

30. Usmanova G, Gresh A, Cohen MA, Kim Y-M, Srivastava A, Joshi CS, Bhatt DC, Haws R, Wadhwa R, Sridhar P, Bahl N, Gaikwad P, Anderson J. Acceptability and barriers to use of the ASMAN provider-facing electronic platform for Peripartum Care in Public Facilities in Madhya Pradesh and Rajasthan, India: a qualitative study using the technology acceptance Model-3. Int J Environ Res Public Health. 2020;17(22):8333. https://doi.org/1 0.3390/ijerph17228333.

31. Hawley G, Jackson C, Hepworth J, Wilkinson SA. Sharing of clinical data in a maternity setting: how do paper hand-held records and electronic health records compare for completeness? BMC Health Serv Res. 2014;4(1):650. https://doi.org/10.1186/s12913-014-0650-x.

32. Kassebaum NJ, Bertozzi-Villa A, Coggeshall MS, Shackelford KA, Steiner C, Heuton KR, Gonzalez-Medina D, Barber R, Huynh C, Dicker D, Templin T, Wolock TM, Ozgoren AA, Abd-Allah F, Abera SF, Abubakar I, Achoki T, Adelekan A, Ademi Z, Adou AK, Adsuar JC, Agardh EE, Akena D, Alasfoor D, Alemu ZA, Alfonso-Cristancho R, Alhabib S, Ali R, al Kahbouri MJ, Alla F, Allen PJ, AlMazroa MA, Alsharif U, Alvarez E, Alvis-Guzmán N, Amankwaa AA, Amare AT, Amini H, Ammar W, Antonio CAT, Anwari P, Ärnlöv J, Arsenijevic VSA, Artaman A, Asad MM, Asghar RJ, Assadi R, Atkins LS, Badawi A, Balakrishnan K, Basu A, Basu S, Beardsley J, Bedi N, Bekele T, Bell ML, Bernabe E, Beyene TJ, Bhutta Z, Bin Abdulhak A, Blore JD, Basara BB, Bose D, Breitborde N, Cárdenas R, Castañeda-Orjuela CA, Castro RE, CataláLópez F, Cavlin A, Chang JC, Che X, Christophi CA, Chugh SS, Cirillo M, Colquhoun SM, Cooper LT, Cooper C, da Costa Leite I, Dandona L, Dandona R, Davis A, Dayama A, Degenhardt L, de Leo D, del Pozo-Cruz B, Deribe K, Dessalegn M, deVeber GA, Dharmaratne SD, Dilmen U, Ding EL, Dorrington RE, Driscoll TR, Ermakov SP, Esteghamati A, Faraon EJA, Farzadfar F, Felicio MM, Fereshtehnejad SM, de Lima GMF, Forouzanfar MH, França EB, Gaffikin L, Gambashidze K, Gankpé FG, Garcia AC, Geleijnse JM, Gibney KB, Giroud M, Glaser EL, Goginashvili K, Gona P, González-Castell D, Goto A, Gouda HN, Gugnani HC, Gupta R, Gupta R, Hafezi-Nejad N, Hamadeh RR, Hammami M, Hankey GJ, Harb HL, Havmoeller R, Hay SI, Pi IBH, Hoek HW, Hosgood HD, Hoy DG, Husseini A, Idrisov BT, Innos K, Inoue M, Jacobsen KH, Jahangir E, Jee SH, Jensen PN, Jha V, Jiang G, Jonas JB, Juel K, Kabagambe EK, Kan H, Karam NE, Karch A, Karema CK, Kaul A, Kawakami N, Kazanjan K, Kazi DS, Kemp AH, Kengne AP, Kereselidze M, Khader YS, Khalifa SEAH, Khan EA, Khang YH, Knibbs L, Kokubo Y, Kosen S, Defo BK, Kulkarni C, Kulkarn VS, Kumar GA, Kumar K, Kumar RB, Kwan G, Lai T, Lalloo R, Lam H, Lansingh VC, Larsson A, Lee JT, Leigh J, Leinsalu M, Leung R, Li X, Li Y, Li Y, Liang J, Liang X, Lim SS, Lin HH, Lipshultz SE, Liu S, Liu Y, Lloyd BK, London SJ, Lotufo PA, Ma J, Ma S, Machado VMP, Mainoo NK, Majdan M, Mapoma CC, Marcenes W, Marzan MB, Mason-Jones AJ, Mehndiratta MM, MejiaRodriguez F, Memish ZA, Mendoza W, Miller TR, Mills EJ, Mokdad AH, Mola GL, Monasta L, de la Cruz Monis J, Hernandez JCM, Moore AR, Moradi-Lakeh M, Mori R, Mueller UO, Mukaigawara M, Naheed A, Naidoo KS, Nand D, Nangia V, Nash D, Nejjari C, Nelson RG, Neupane SP, Newton CR, Ng M, Nieuwenhuijsen MJ, Nisar MI, Nolte S, Norheim OF, Nyakarahuka L, Oh $H_{\text {, }}$ 
Ohkubo T, Olusanya BO, Omer SB, Opio JN, Orisakwe OE, Pandian JD, Papachristou C, Park JH, Caicedo AJP, Patten SB, Paul VK, Pavlin BI, Pearce N, Pereira DM, Pesudovs K, Petzold M, Poenaru D, Polanczyk GV, Polinder S, Pope D, Pourmalek F, Qato D, Quistberg DA, Rafay A, Rahimi K, RahimiMovaghar V, ur Rahman S, Raju M, Rana SM, Refaat A, Ronfani L, Roy N, Pimienta TGS, Sahraian MA, Salomon JA, Sampson U, Santos IS, Sawhney M, Sayinzoga F, Schneider IJC,Schumacher A, Schwebel DC, Seedat S, Sepanlou SG, Servan-Mori EE,Shakh-Nazarova M, Sheikhbahaei S, Shibuya K, Shin HH, Shiue I, Sigfusdottir ID, Silberberg DH, Silva AP, Singh JA, Skirbekk V, Sliwa K, Soshnikov SS, Sposato LA, Sreeramareddy CT, Stroumpoulis K, Sturua L, Sykes BL, Tabb KM, Talongwa RT, Tan F, Teixeira CM, Tenkorang EY, Terkawi AS, Thorne-Lyman AL, Tirschwell DL, Towbin JA, Tran BX, Tsilimbaris M, Uchendu US, Ukwaja KN, Undurraga EA, Uzun SB, Vallely AJ, van Gool CH, Vasankari TJ, Vavilala MS, Venketasubramanian N, Villalpando S, Violante FS, Vlassov W, Vos T, Waller S, Wang H, Wang L, Wang XR, Wang Y, Weichenthal S, Weiderpass E, Weintraub RG, Westerman R, Wilkinson JD, Woldeyohannes SM, Wong JQ,Wordofa MA, Xu G, Yang YC, Yano Y, Yentur GK, Yip P, Yonemoto N, Yoon SJ, Younis MZ, Yu C, Jin KY, el Sayed Zaki M, Zhao Y, Zheng Y, Zhou M, Zhu J, Zou XN, Lopez AD, Naghavi M, Murray CJL, Lozano R. Global, regional,and national levels and causes of maternal mortality during 1990-2013: a systematic analysis for the global burden of disease study 2013. Lancet.2014;384(9947):980-1004. https://doi.org/10.1016/S01406736(14)60696-6.

33. Say L, Chou D, Gemmill A, Tunçalp Ö, Moller AB, Daniels J, Gülmezoglu AM, Temmerman M, Alkema L. Global causes of maternal death: a WHO systematic analysis. Lancet Global Health. 2014;2(6):e323-33. https://doi. org/10.1016/S2214-109X(14)70227-X.

34. Lawn JE, Blencowe H, Waiswa P, Amouzou A, Mathers C, Hogan D, Flenady V, Frøen JF, Qureshi ZU, Calderwood C, Shiekh S, Jassir FB, You D, McClure EM, Mathai M, Cousens S, Flenady V, Frøen JF, Kinney MV, de Bernis L, Lawn JE, Blencowe H, Heazell A, Leisher SH, Azad K, Rahman A, elArifeen S, Day LT, Shah SL, Alam S, Wangdi S, Ilboudo TF, Zhu J, Liang J, Mu Y, Li X, Zhong N, Kyprianou T, Allvee K, Gissler M, Zeitlin J, Bah A, Jawara L, Waiswa P, Lack N, de Maria Herandez F, Shah More N, Nair N, Tripathy P, Kumar R, Newtonraj A, Kaur M, Gupta M, Varghese B, Isakova J, Phiri T, Hall JA, Curteanu A, Manandhar D, Hukkelhoven C, Dijs-Elsinga J, Klungsøyr K, Poppe O, Barros H, Correia S, Tsiklauri S, Cap J, Podmanicka Z, Szamotulska K, Pattison R, Hassan AA, Musafi A, Kujala S, Bergstrom A, Langhoff -Roos J, Lundqvist E, Kadobera D, Costello A, Colbourn T, Fottrell E, Prost A, Osrin D, King C, Neuman M, Hirst J, Rubayet S, Smith L, Manktelow BN, Draper ES. Stillbirths: rates, risk factors, and acceleration towards 2030. Lancet. 2016; 387(10018):587-60. https://doi.org/10.1016/S0140-6736(15)00837-5.

35. Praveen D, Patel A, Raghu A, Clifford GD, Maulik PK, Mohammad Abdul A, Mogulluru K, Tarassenko L, MacMahon S, Peiris D, SMARTHealth India. Development and field evaluation of a mobile clinical decision support system for cardiovascular diseases in rural India. JMIR Mhealth Uhealth. 2014;2(4):e54. https://doi.org/10.2196/mhealth.3568.

36. Anchala R, Kaptoge S, Pant H, Di Angelantonio E, Franco OH, Prabhakaran D. Evaluation of effectiveness and cost-effectiveness of a clinical decision support system in managing hypertension in resource constrained primary health care settings: results from a cluster randomized trial. J Am Heart Assoc. 2015;4(1). https://doi.org/10.1161/JAHA.114.001213.

37. Msemo G, Massawe A, Mmbando D, Rusibamayila N, Manji K, Kidanto HL, Mwizamuholya D, Ringia P, Ersdal HL, Perlman J. Newborn mortality and fresh stillbirth rates in Tanzania after helping babies breathe training. Pediatrics. 2013;131(2):e353-60. https://doi.org/10.1542/peds.2012-1795.

38. Moja L, Kwag KH, Lytras T, Bertizzolo L, Brandt L, Pecoraro V, Rigon G, Vaona A, Ruggiero F, Mangia M, lorio A, Kunnamo I, Bonovas S. Effectivenessof computerized decision support systems linked to electronic health records: a systematic review and meta-analysis. Am J Public Health. 2014;104(12): e12-22. https://doi.org/10.2105/AJPH.2014.302164.

\section{Publisher's Note}

Springer Nature remains neutral with regard to jurisdictional claims in published maps and institutional affiliations.

\section{Ready to submit your research? Choose BMC and benefit from}

- fast, convenient online submission

- thorough peer review by experienced researchers in your field

- rapid publication on acceptance

- support for research data, including large and complex data types

- gold Open Access which fosters wider collaboration and increased citations

- maximum visibility for your research: over $100 \mathrm{M}$ website views per year

At BMC, research is always in progress.

Learn more biomedcentral.com/submissions 